\title{
HOW NOT TO REJECT THE A PRIORI*
}

\author{
Célia Teixeira** \\ celia.teixeira@gmail.com
}

RESUMO Segundo um influente argumento contra a existência de conhecimento a priori, não há conhecimento a priori porque (i) nenhuma crença é imune à revisão, e (ii) se houvesse conhecimento a priori, algumas crenças seriam irrevisíveis. Uma versão deste argumento foi celebremente defendida por $W . V$. Quine e ainda é popular entre filósofos naturalistas. $O$ objectivo deste artigo é examinar e rejeitar este argumento contra o a priori. $O$ artigo começa por discutir a tese (i) e o seu papel no modelo da Teia de Crenças de Quine. Defende-se que (i) enfrenta importantes desafios que colocam em risco o seu uso no argumento supra. A premissa (ii) do argumento é então discutida. Philip Kitcher é conhecido pela sua defesa de uma versão da premissa (ii). Os seus argumentos são analisados e rejeitados. A conclusão é que não temos uma boa razão para aceitar (ii), e consequentemente este argumento contra o a priori. O artigo termina com a proposta de uma caracterização do a priori perfeitamente compativel com (i).

Palavras-chave A priori, conhecimento, revisabilidade, revisável, empirismo, teia de crenças.

ABSTRACT According to one influential argument against the existence of a priori knowledge, there is no a priori knowledge because (i) no belief is immune to revision, and (ii) if there were a priori knowledge, at least some beliefs would be unrevisable. A version of this argument was famously advocated by W. V. Quine, and is still popular among many naturalist philosophers. The aim of this paper is to examine and reject this argument against the a priori. The

* Artigo submetido em 15/04/17. Aceito em 07/08/17.

** Universidade Federal do Rio de Janeiro (UFRJ). Rio de Janeiro - RJ - Brasil.

KRITERION, Belo Horizonte, n 140, Ago./2018, p. 365-384 
paper starts by discussing the thesis (i) and its role in Quine's Web of Belief model. It is suggested that this thesis faces some important challenges that might jeopardize its use in the above argument against the a priori. Premise (ii) of the argument is then discussed. Philip Kitcher has famously defended a version of premise (ii). His arguments are assessed and rejected. The conclusion is that we have no good reason to accept (ii), and, with it, this argument against the a priori. The paper ends by proposing an account of the a priori that is perfectly compatible with (i).

Keywords: A priori, knowledge, revisability; revisable, empiricism, Web of Belief.

\section{Introduction}

One popular reason to claim that there is no a priori knowledge results from the acceptance of the following thesis: no belief is immune to revision. ${ }^{1}$ Let us call this thesis, the Revisability Thesis. This thesis, famously advocated by W. V. Quine (1951), had a dramatic impact in $20^{\text {th }}$ century philosophy, leading to the demise of logical positivism, and it still occupies central stage in many contemporary debates. ${ }^{2}$ One of those debates concerns the existence of a priori knowledge. That is the debate that will concern us here. Someone who claims that 'if no belief is immune to revision, then there is no a priori' is implicitly assuming that if a belief is justified a priori, then it is unrevisable. And if both these claims are true, it follows that no belief is justified a priori. If no belief is justified a priori, then there is no a priori knowledge. Here is the argument:

(Revisability Thesis - RT) No belief is immune to revision.

(Unrevisability Thesis - UT) If a belief is justified a priori, then it is unrevisable.

Therefore, no belief is justified a priori, and there is no a priori knowledge ${ }^{3}$

1 The original formulation of this thesis by Quine (1951) was in terms of statements, but it has also been widely understood in terms of belief. I shall follow this latter understanding of the thesis to make the connection with the a priori clearer, but nothing of importance to my argument hangs on this. However, strictly speaking, it is not clear how one could revise a statement, but it is clear that one can revise our attitudes towards a statement, such as the attitude of believing its truth.

2 In Teixeira (2018) I argue that the Revisability Thesis is in fact ambiguous between three substantially different theses. In this paper I focus on the strongest reading of the thesis. I claim that even if we were to accept such a reading of the thesis, we would still have no good reason to accept the claim that if a belief is justified a priori then it is unrevisable.

3 I'm assuming knowledge to be a special kind of belief, but nothing of importance to my claim hangs on this. 
Let us call this argument, the Revisability Argument. The main aim of this paper is to examine, and reject this argument against the a priori.

The paper proceeds as follows. First I motivate (RT) by assessing its role in Quine's Web of Belief model. I claim that (RT) is a substantive and interesting claim, but one that faces some serious challenges. However, for argument's sake, I will accept (RT), and move on to examine the second premise of Revisability Argument, namely (UT). I review some of the historical reasons in support of (UT), and find them wanting. Philip Kitcher (1980 and 1984) has given some of the best arguments in favour of this unrevisability condition on the a priori. His arguments are thus assessed and rejected. The conclusion is that we should reject (UT) and, with it, the Revisability Argument against the a priori. I conclude by proposing an account of the a priori that is perfectly compatible with (RT).

\section{The Web of Belief}

Why should we accept that nothing is immune to revision? (RT) seems quite an extraordinary claim. After all, what could make us revise such basic beliefs as the belief that either it will rain or not rain, or that two plus two equals four? Some of our beliefs do seem to enjoy a special epistemic (and modal) status. Moreover, the certainty with which we hold a priori truths seems to be more than a mere conviction on our part that they could not fail to be true. How do we account for that? How can such truths be revisable?

Quine (1954) claims that the question "How is logical certainty possible?" is 'less tendentious' and 'logically prior' than the question "How is a priori knowledge possible?". However, by this he does not mean that we need to account for the psychological characteristic that we have toward certain logical truths, even if his answer is somewhat psychologistic. ${ }^{4}$ The claim is rather that we need to account for the apparent difference in modal and epistemic status that logical and mathematical truths seem to enjoy.

The logical positivist answer to Quine's question "How is logical certainty possible?" was that logical truths were true by convention, and so we could never doubt them. Those truths were also thought to be such that we could know them to be true just by understanding their meanings; and given that they were taken to lack factual content, nothing could override them. ${ }^{5}$ The logical positivist

4 It should be noted that Quine (1954) considers instead Kant's question "How are synthetic judgments a priori possible?", but this is not relevant for our current purposes.

5 We have nowadays very good reasons to doubt this non-factualist claim about the a priori (and the analytic), which Quine (1951), to my mind, rightly rejected. For more on this, see, e.g., Boghossian (1997), and Williamson (2007). 
account of the a priori is a compromise between two apparently incompatible claims: (i) that there is a priori knowledge, and (ii) that all knowledge is grounded in experience. Quine endorsed an uncompromising empiricism. With Quine's empiricism we could reject the a priori and explain, at the same time, the apparent epistemic and modal difference that mathematical and logical truths seem to enjoy.

At the end of "Two Dogmas of Empiricism", Quine formulates what came to be known as the Web of Belief model, which expresses his uncompromising empiricism:

The totality of our so-called knowledge or beliefs, from the most casual matters of geography and history to the profoundest laws of atomic physics or even pure mathematics and logic, is a man-made fabric which impinges on experience only along the edges. Or to change the figure, total science is like a field of force whose boundary conditions are experience. A conflict with experience at the periphery occasions readjustments in the interior of the field. Truth values have to be redistributed over some of our statements. Re-evaluation of some statements entails re-evaluation of others, because of their logical interconnections - the logical laws being in turn simply certain further statements of the system, certain further elements of the field. Having re-evaluated one statement we must re-evaluate some others, which may be statements logically connected with the first or may be the statements of logical connections themselves (Quine, 1951, p. 42).

Some clarifications are in order. If our web of beliefs is a "man-made fabric" does this mean that we are free to change our beliefs at will? For instance, if we find out that we only have two notes of five Euros in our wallet, can we change the belief that two times five is ten in order to preserve our former belief that we have twenty Euros in our wallet? This would be an irrational move, one that a rational agent must not follow. The Web of Belief is an epistemic web, one whose aim is truth. Obviously, an irrational agent could make the most extraordinary changes in his web of beliefs. However, an epistemic web must be a rational web, and revisions in the web must be rationally made. Moreover, by ceasing to believe that two times five is ten we would have to make other changes in our web. We would have to change those beliefs logically connected to this one, namely most, if not all of our arithmetic beliefs. In this case, denying such an arithmetic belief would introduce arbitrary complexities in our web, which would inevitably disrupt it. To keep and preserve the well-being of our web we must keep changes at a minimum in order to allow it to grow in an orderly and coherent fashion. As rational agents, one ought to carefully determine the impact of certain changes in our web of beliefs.

However, keeping a tidy and coherent web, even if necessary, is not sufficient for its well-being. Imagine a very simple web that allowed someone to survive. 
Such an agent could refuse to accept any new beliefs in order not to disrupt the coherence of his web. But such a refusal would also be irrational. If we are faced with new evidence, we ought to incorporate it in our web - unless we have a stronger reason not to do so. A healthy web is also a web that grows and changes, one that allows us to increase our knowledge of the world and interact successfully with it.

In light of this, it is reasonable to think that it would be impossible to revise any of our core logical beliefs. Such changes would disrupt, and most certainly endanger, the whole of our web of beliefs. In fact, this led Quine (1970) to claim that massive revisions in our physical beliefs are always less disruptive, and as such, preferable, to revisions in our logical beliefs. ${ }^{6}$

The web is connected by logical rules; loss of these connections would maximally disrupt the entire web, rendering it unintelligible. The reorganization of our web would, thus, become an impossible task, for all we would have to go on with would be an unintelligible aggregate of beliefs. However, changes never occur in such a drastic manner. The fact that all our core logical connective rules can be revised does not mean that we could revise them all at once, or even in such a drastic manner. Changes are always gradual. We could, for instance, start by doubting one core logical belief without revising it immediately. Such doubts could progressively change the status of such belief as a core belief. This is probably what has happened when people started doubting Euclidean geometry. We started by considering some evidence for non-Euclidean geometries that allowed us to question whether space is Euclidean. Such new evidence imposes certain changes in our web: new beliefs are formed, others abandoned, and new links created until we reach a point in which the addition of such a new belief becomes possible, or even rationally mandatory.

But how can this help us explain the apparent epistemic and modal difference that mathematical and logical truths seem to enjoy? In other words, why is it that some of our beliefs do seem unrevisable?

According to Quine's model, logical and mathematical beliefs are confirmed and disconfirmed in exactly the same way as scientific beliefs. Since they are all part of our web of beliefs, they are subject to the same rules of the web as any other belief. Given that we are inclined (as we should) to make the least rationally possible modifications in our web of beliefs, we tend to make the readjustments with experience at the periphery instead of doing them at the core, where the logical beliefs are located. This suggests that the more central a

6 This indicates a slight change from his earlier view as stated in "Two Dogmas". For more on this, see Dummett (1976). 
belief is the more secure or less susceptible to revision it tends to be. We saw just how difficult it would be to change some of our core logical and mathematical beliefs. Such beliefs occupy such a central place in our web that we find it almost unimaginable to call them into question. They do enjoy a special status in our web. Nonetheless, according to Quine, this does not mean that they are necessary or a priori or analytic, it just means that they are more central. And it is because of this centrality, Quine claims, that we have the illusion that they enjoy a different epistemic and modal status. According to him, such an illusion is also fuelled by the fact that core beliefs are involved in more interconnections, which results in the fact that they are also more often confirmed by experience.

\section{Some Initial Worries}

Quine's Web of Belief model has been widely discussed and criticised. ${ }^{7}$ One of the most obvious worries, and one that has often been raised, is the fact that it seems incoherent. And if the Web of Belief Model is incoherent, we lose the motivation to accept (RT). Let us look in more detail to this worry.

(RT) is one of the constitutive principles of the web. But there are, at least, two others: the principle of non-contradiction and the principle of simplicity (also called the principle of minimum mutilation). The principle of non-contradiction tells us when we should readjust our web, namely, when it contradicts some observations. The principle of simplicity tells us which sentences we should revise, given that we do not want to make drastic changes in our web. As we saw, (RT) tells us that nothing is "immune to revision", that everything is revisable, even those beliefs that are at the core of the web.

In the famous passage from "Two Dogmas" quoted in the previous section, Quine seems to claim that logic has a special role in the web of belief by regulating the links between beliefs. However, some lines below that passage he goes on to make a somewhat more radical claim:

Any statement can be held true come what may, if we make drastic enough adjustments in the system. Even a statement very close to the periphery can be held true in the face of recalcitrant experience by pleading hallucination or by amending certain statements of the kind called logical laws. Conversely, by the same token, no statement is immune to revision. Revision even of the law of the excluded middle has been proposed as a means of simplifying quantum mechanics; and what difference is there between such a shift and the shift whereby Kepler superseded Ptolemy, or Einstein Newton, or Darwin Aristotle? (Quine, 1951, p. 43) 
It is (RT), the claim that all our beliefs are, in principle, revisable, including logic, which is the central tenet of this form of empiricism. It is (RT) that demotes logic from its special epistemological status and places it at the same level as any other field.

Now, the charge of incoherence that has been levelled against the Web of Belief comes from the fact that (RT) seems to collide with the principle of non-contradiction and with itself. ${ }^{8}$ It seems to collide with the principle of non-contradiction because, given that it is a constitutive principle of the web, it is not the case that everything is revisable. If it were revised we would lose the main principle used to guide us as to which beliefs to revise. Without such a principle our web could end up as a chaotic set of beliefs where anything goes. We could end up believing that water is and is not $\mathrm{H}_{2} \mathrm{O}$ given that there would be nothing to constrain our web. Let me elaborate.

Assume that we reject the principle of non-contradiction in order to simplify our web of beliefs. Now imagine that we see a white raven and that one of our beliefs in the web is the belief that all ravens are black. Without the principle of non-contradiction we would have no reasons to revise the belief that all ravens are black or any other belief connected to this one. In these circumstances, we could incorporate in our web the belief that some ravens are white together with the belief that all ravens are black - which is incoherent. And, thus, there would be no such thing as a real conflict with experience; there would be no constraints about what we should or not revise in the face of a recalcitrant experience. Without the principle of non-contradiction to impose certain constraints on our web we could stop adjusting it to experience. The web would in this way become a mere aggregate of beliefs, and possibly, an incoherent one. And a possibly incoherent aggregate of beliefs does not satisfy the requirements for knowledge, nor for rationality. Without some form of the principle of noncontradiction our web wouldn't work as an epistemic model.

The point here is not so much that it is irrational to believe in contradictions - though I think it is. The problem is that we need to know when our web needs revision, how are we to adjust it in the face of a recalcitrant experience. So even if we admit that some contradictions are true, say, by adopting a paraconsistent logic, most of them are false. Of course, if we accept dialetheism - i.e., the view that there are true contradictions - then we are already revising our principle of non-contradiction, adding support to Quine's empiricism. However, we would nonetheless need a weaker form of the principle of non-contradiction to

8 Katz (1998, pp. 72-77) accuses Quine's epistemology of giving rise to paradoxes because it follows from it that there are statements that can and cannot be revised. 
regulate the well-being of our web. Without, at least, some weaker version of the principle of non-contradiction, a thinker who believes that $p$ when presented with a recalcitrant experience to the effect that not- $p$ (or with an argument to the effect that not- $p$ ) could simply accept both $p$ and not- $p$, for every $\mathrm{p}$. And this is rationally unacceptable: thinkers should rationally revise their beliefs when faced with stronger evidence to the contrary. So, even if we accept that some contradictions are true, such as, say, the liar sentence - the sentence that states of itself that it is false - we do not have to, and in fact should not, accept that all are on pain of irrationality ${ }^{9}$

So even if we were to admit that some contradictions are true, we would still need a weaker version of the principle of non-contradiction to regulate the well-being of our Web of Belief. Something like: most statements are not both true and false, or, following Putnam (1978) famous example, not every statement is both true and false. Now, the question is: Is a weaker version of the principle of non-contradiction revisable? If it is, all seems, in principle, well. If it is not, then, it is false that everything is revisable.

Now, according to this weaker version of the principle of non-contradiction, not every statement is both true and false. From this is follows that,

(1) At least one statement is either true or false.

And rejecting (1) entails accepting its negation as true, namely that,

(2) Every statement is both true and false.

And (2) is something that no rational being could possibly accept. Therefore, (1) is unrevisable, since it is rationally impossible to accept its negation as true for that would lead us to accept and reject every statement. Hence, it is not the case that everything is revisable. ${ }^{10}$

(RT) also seems to be unrevisable, contrary to what it states. To say that everything is revisable is to say that even the thesis that everything is revisable is revisable. But if this thesis were revised and rejected, then it would not be the case that everything is revisable. And we end up with another incoherence in the web.

We could claim that there are exceptions, that we could not apply (RT) to any of the constitutive principles of the web. But this strategy is not satisfactory since it goes against Quine's empiricist project itself. If we allow exceptions, these principles would stop having the same status the empirical statements

9 If we take entailment to be explosive, i.e., that from a contradiction everything follows, accepting one contradiction is enough to accept them all. However, by accepting that there are some true contradictions we would have to reject explosion and assume that entailment is paraconsistent. Whether entailment is explosive or paraconsistent is not something that should concern us here.

10 Putnam (1978). 
have - and the motivation was precisely to reject, among other things, a different status to the truths of logic and mathematics. Accepting such a solution would result in the rejection of the core thesis behind Quine's model, namely, that all beliefs, or "the totality of our so-called knowledge or beliefs", face the "tribunal of experience as a corporate body".

Marcus Giaquinto (1996) claims that probably we could revise even Putnam's weaker principle of non-contradiction by realising in the course of our investigation that truth is relative to a language fragment, and that truth is a matter of degree so that nothing is true to degree 1 or false to degree 0 . In this case, the rejection of "At least one L-statement is either L-true or L-false" would not lead us to the absurd position of accepting and rejecting every statement, for if there were degrees of truth, we would only accept every statement to a certain degree relative to a certain language, and reject them to a different degree relative to a certain language fragment. However, Giaquinto admits that probably he would not be able to fill out the whole story in a coherent way. Nevertheless, he claims,

[...] this would show only the limits of my ability to conceive certain possibilities. It is not part of the Quinean position that for any current belief, however firmly held, we are currently able to imagine a set of circumstances in which it would be rational to reject it. On the contrary, we may explain the common conviction that some sentence is unrevisable as due to a current inability to conceive of circumstances in which it would be rational to reject it. Quine's claim is merely that, for any dictum, such circumstances might obtain, not that we can currently conceive of them (Giaquinto, 1996, p. 253).

Giaquinto's strategy might very well prove to be the best way of supporting (RT). However, one might insist that his strategy fails to provide a positive argument for (RT). However, it does seem clear, even if just from our current epistemic situation, that certain claims are unrevisable. For example, consider the belief that some beliefs are revisable. Whatever reason we could have to revise it would also be a reason to accept it, thus becoming, purportedly, rationally unrevisable. Insisting that even such a belief could, in principle, be revised seems to beg important questions. After all, one could equally insist that such a belief is indeed unrevisable. Conceivability arguments of this sort can go both ways, making them less convincing than they might at first seem.

I do not claim that these considerations offer a knockdown argument against (RT). ${ }^{11}$ However, they undermine its initial plausibility. For, even if (RT) enjoys a good degree of plausibility, so does the negation of (RT). And in order to 
use (RT) as premise in the Revisability Argument, we need it to be more than a plausible claim, we need the conjunction of the premises of the argument to be independently more plausible than the negation of its conclusion. And it is not clear that (RT) is more plausible than the claim that there is no a priori knowledge, thus putting considerable pressure in the cogency of the argument. ${ }^{12}$

However, I will not dwell further on this, for the Revisability Argument faces a more pressing problem. Even if we were to concede that (RT) is more plausible than the claim that there is no a priori knowledge, we have no good reason to accept that a priori beliefs are unrevisable, that is, premise (UT) of the argument. If so, then (RT), even if true, is perfectly consistent with the existence of a priori knowledge.

\section{A Priori Revision}

Historically, many rationalists have been taken to claim that the a priori is unrevisable by any lights, that is, that we can have neither a priori nor a posteriori reasons to reject an a priori belief. For these philosophers a priori justification yields knowledge and we could never doubt such truths - a priori beliefs were thus taken to be unrevisable by any lights. The most popular of such truths is Descartes' cogito. ${ }^{13}$ But mathematical and logical truths were also thought to be of such kind: unrevisable both by a priori and by a posteriori means. Classical rationalists claimed that a priori beliefs were to be explained as the product of a special faculty - viz., rational intuition - and such a rational faculty was thought to be an infallible way of arriving at the truth, and the truths so arrived at, unrevisable.

Despite its historical credentials, the claim that the a priori is unrevisable by any lights has lost most of its initial appeal. By claiming that a priori beliefs must be unrevisable by any lights we are assuming that a priori justification is stronger than a posteriori justification, so much stronger that it does not admit the revision of the belief thus justified. In other words, the claim here is that we could never have any sort of reasons to reject a belief acquired through an a priori source of justification. One motivation for such a claim is to take our a priori sources of knowledge and justification to be infallible or ultra-reliable in the sense that we could never doubt their results. If a belief is acquired through an a priori source of justification, then we could never have reason to doubt it. But why assume a priori justification to be stronger than a posteriori 
justification? The plausibility of such dissimilarity will depend on the plausibility of the argument to that effect; otherwise, as Albert Casullo (2003) claims, the dissimilarity should be rejected as ad hoc.

However, the claim that our a priori sources of justification are infallible found contemporary support in the work of Philip Kitcher (1984). Kitcher is well known for his characterization of the a priori according to which our a priori sources of justification must be ultra-reliable. And, if a priori justification is indeed ultra-reliable, then if we came to believe that $p$ a priori, we could never then come to believe that not- $p$ in the same way, that is, a priori. Here is how he supports this assumption:

The intuition is that a priori warrants must be ultra-reliable: if a person is entitled to ignore empirical information about the type of world she inhabits then that must be because she has at her disposal a method of arriving at belief that guarantees true belief. (This intuition can be defended by pointing out that if a method which could produce false belief were allowed to override experience, then we might be blocked from obtaining knowledge which we might otherwise have gained.) (Kitcher, 1984, pp. 29-30).

Kitcher's argument for the ultra-reliability of our a priori sources of justification boils down to the claim that if our a priori sources of justification did not yield truth we could end up overriding a true belief with a false one, thus blocking the possibility of 'gaining knowledge which we might otherwise have gained'. For example, suppose that I was a posteriori justified, say, by perception, to believe that $p$. Suppose also that I come to believe through an a priori source of justification, say, by reflection, that not- $p$. If this source of a priori justification were not ultra-reliable, so the argument goes, my a priori belief that $p$ could have been false, thus overriding my a posteriori true belief that not- $p$ - blocking me from obtaining knowledge that I might otherwise have gained. However, Kitcher's argument will not work to justify the ultra-reliability condition on a priori sources of justification and with it the unrevisability of a priori beliefs. Let us see why.

First, the danger of overriding true beliefs, and thus blocking us from obtaining knowledge that we might otherwise have gained, also applies to our a posteriori sources of justification. For example, suppose that I smell baking apple pie that seems to be coming from my neighbour's kitchen, thus forming the belief that my neighbour is at home baking an apple pie. Now, suppose that I do not see her car parked outside, as it normally is when my neighbour is at home. Given this new piece of information, I override my previous belief that my neighbour is at home baking an apple pie, and form the belief that my neighbour is not at home baking an apple pie. Finally, suppose that my 
neighbour had just returned from work and that she had left the car in a garage for servicing before returning home, thus explaining the absence of her car from the parking lot outside her home. Suppose also that she was in fact at home baking an apple pie. This seems a plausible case, one that shows that my a posteriori belief based on my keen sense of smell can be overridden by further empirical information, in this case obtained by sight.

Now, purportedly, my sense of smell is a reliable source of justification, as is my vision. But, in this case, the justification I have for the belief that my neighbour is not at home baking a pie is, we assume, stronger than the one I have for the contrary belief, and so I rationally override my previous belief acquired a posteriori and form the belief that my neighbour is not at home baking an apple pie. By overriding an a posteriori true belief with an a posteriori false belief I was blocked from knowing that my neighbour was at home baking and apple pie that I might otherwise have gained if it were not for that other piece of information.

However, we do not take this sort of examples to show that a posteriori sources of justification must be ultra-reliable, or that vision must be an ultrareliable source of justification if it is to override other perceptual sources. So, if from the fact that we can have a false a posteriori belief overriding a true a posteriori belief does not follow that a posteriori sources of justification must be ultra-reliable, then we also have no good reason to assume that our a priori sources of justification must be ultra-reliable if they can override experience. The possible conflicts we have between different sources of a posteriori justification - sight, smell, etc. - do not suffice to conclude that such sources must be ultrareliable. And without further argument we can assume the same to be true of our a priori sources of justification. ${ }^{14}$

We also seem to have an overwhelming amount of empirical evidence against the a priori unrevisability of the a priori. There are plenty of compelling examples of propositions and inferences that were justified a priori that later came to be revised. Such examples seem to be enough to disprove the a priori revisability thesis..$^{15}$ The clearest of such examples are those taken from mathematics and logic. It is very common to revise a pseudo-proof after discovering a mistake in it by pure thought alone.

14 In fact, we have good reason to claim that most of our a priori beliefs are actually compatible and avowed by our a posteriori beliefs (e.g., if we have two plus two bananas we will observe we have four bananas). See Bealer (1992) for more on this. See also Casullo (2003) for a similar claim.

15 Disregarding such examples by claiming that they are not cases of a priori beliefs because they were revised is clearly question begging, and so not a sound move for an empiricist to take. 
It is clear that some pseudo-proofs cannot provide epistemic support to believe in their conclusion. For example, imagine that a really bad logic student is trying to prove that a certain proposition is a theorem. He is incapable of understanding the rules of inference but uses them anyway in a sort of pick and choose manner. Such a pseudo-proof - if we may call it that - does not provide any rational support for its conclusion; and such a student is justified to degree zero in believing the conclusion of his 'proof'. However, a student who understands the rules, who carefully examines every step, but still gets it wrong is epistemically justified in believing in the conclusion of her "pseudoproof'. Or, take the now famous case of Andrew Wiles. The first proof that Wiles presented of Fermat's Last Theorem was in fact flawed. But he did not commit any epistemic sin by believing that he had a proof of Fermat's last theorem. He had good reason to hold such a belief, despite being wrong. It would be absurd to deny that Wiles did not come to believe in the soundness of his first proof independently of experience just because it had a flaw that he himself later came to realise non-experientially.

Ethical claims also seem to be a priori. ${ }^{16}$ In normative ethics we have virtue theories, deontological theories, and consequentialist theories, and they cannot all be true. So some, if not all, are a priori revisable. The same can be said of the claims of other branches of philosophy: they are justified a priori and disputed on a priori grounds.

A more promising claim is the claim that the a priori is empirically unrevisable. It is to this claim that I will now turn.

\section{Empirical Revision}

Maybe we can have a priori reasons to revise our a priori beliefs, but it seems that we will not be able to get a posteriori reasons to revise our a priori beliefs. The idea is that if an a priori belief is revisable in the light of experience, then it might not be independent of experience. The question now is whether a priori beliefs are empirically unrevisable. My aim is to show that they are not, that we can empirically revise our a priori beliefs.

The thesis that the a priori is empirically unrevisable is a much more plausible and popular thesis. This is in fact the one that is at the heart of the Quinean rejection of the a priori. ${ }^{17}$ But what reasons do we have to support the

16 See Peacocke (2004, pp. 198-220) for an argument to that effect.

17 For instance, Devitt (2005) formulates the revisability thesis with this qualification of empirical revisability. This is also the thesis endorsed by Kitcher (1980). 
idea that the a priori must be empirically unrevisable? The motivation is never clear. Despite that, some philosophers assume that if nothing is immune to empirical revision, then there is no a priori knowledge. Kitcher (1980 and 1984) is, to my knowledge, the only philosopher to explicitly offer an argument for the empirical unrevisability of the a priori. It is to his arguments that I now turn.

In his famous analysis of the a priori, Kitcher presents the following condition for a priori justification: ${ }^{18}$

$\alpha$ is an a priori warrant for $X$ 's belief that $\mathrm{p}$ if and only if $\alpha$ is a process such that, given any life $e$, sufficient for $X$ for $p,[\ldots]$ (b) if a process of the same type were to produce in $X$ a belief that $p$, then it would warrant $X$ in believing that $p$. (Kitcher 1984, p. 24)

By 'any life $e$ sufficient for $X$ for $p$ ' Kitcher means any life sufficient to allow subject $X$ to believe that $p$. For example, we cannot know that no object can be green and red all over at the same time, without having acquired the concepts green and red - that is, without having had a life sufficient for the acquisition of those empirical concepts. But once we have acquired such concepts, once we have had the experiences necessary for the acquisition of such concepts, we can come to know a priori that no object can be green and red all over at the same time.

Kitcher's condition (b) has been widely discussed and rejected as too strong. ${ }^{19}$ After all, we can easily think of examples in which, say, a mathematician came to believe in a certain proposition through the process of following a proof (a purportedly a priori source of justification), that the community of mathematicians mistakenly regarded it as flawed and as having a proof that such a proposition was false, thus overriding the mathematician's belief. ${ }^{20}$ If so, following a proof cannot be regarded as a source of a priori justification, for it fails to meet condition (b). But this is a very implausible result. So the question now is why should we accept condition (b)? Why should we accept that in order for us to be a priori justified in believing $p, p$ cannot be empirically rejected? Here is what Kitcher says in support of condition (b):

To make this concession is to abandon the fundamental idea that a priori knowledge is knowledge which is independent of experience. The apriorist would be saying that one

18 Kitcher uses the term 'warrant' for belief-forming processes. I will continue to use the term 'justification' broadly understood, unless stated otherwise.

19 See, for instance, Hale (1987), Summerfield (1991), and Casullo (1998 and 2003).

20 Kitcher talks of direct, theoretical and social ways of experimentally overriding or undermining a belief - though he does not distinguish undermining defeaters from overriding ones. The example presented is of a social challenge. Such distinctions, however, are not important for our present purposes. See Bonjour (1998, pp. 121-24) for a discussion of these distinctions. 
can know a priori that $p$ in a particular way, even though, given appropriate experience, one would not be able to know that $p$ in the same way. But if alternative experiences could undermine one's knowledge then there are features of one's current experience which are relevant to the knowledge, namely those features whose absence would change the current experience into the subversive experience (Kitcher, 1984, pp. 88-9).

Kitcher does not distinguish overriding from undermining defeaters, but it seems clear that he must be thinking of overriding defeaters. An undermining defeater defeats the source of the justification, not the claim itself. So having an undermining defeater for $p$ does not give us reasons in favour of not- $p$, it only give us reasons to think that the justification we have for $p$ is (possibly) no good. However, an overriding defeater defeats $p$ itself. So only when experience could affect the truth of the statement itself can we plausibly say that in this way the statement cannot be known independently of experience. And it seems that this is what Kitcher has in mind when he says that "[...] if alternative experiences could undermine one's knowledge then there are features of one's current experience which are relevant to the knowledge".

Kitcher's main claim is that if experience could override a thinker's a priori belief that $p$, then $p$ is not suitably independent of experience for it depends on the current experience having as a feature the absence of the subversive experience. To make this point clear, imagine, for example, that I came to believe that $p$ after proving that $p$ (a purported source of a priori justification). Imagine further that if I had encountered a certain leading mathematician I would have rejected my belief that $p$, for she would have told me that $p$ is false and I would have been rationally compelled to take her word for it. If we assume that testimony is an a posteriori source of justification, this subversive experience would have led me to believe a posteriori that not- $p$. So it does seem that my belief that $p$ depends, to a certain extent, on the absence of such a subversive experience in the sense that had I had that subversive experience, I would not have been justified in believing that $p$.

Now imagine that I was in fact right, that my proof was sound, that $p$ was true, but that there is a possible subversive experience in which the mathematician misleadingly leads me to reject that $p$. According to Kitcher, my belief that $p$, though true and produced by a sound proof (a purported a priori process) would be a posteriori, for it would depend on the absence of such a subversive experience. But this is implausible. For even if we concede that my belief that $p$ counterfactually depends on experience in this weak sense, it does not depend on experience insofar as it was produced and sustained by a purported a priori process that conferred justification upon it - namely, the proof.

To make this last point clearer, we can appeal to a distinction between strong and weak dependence understood in the following way: $S$ 's belief that $p$ 
strongly depends on experience if and only if experience produces and sustains the belief that $p$; and $S$ 's belief that $p$ weakly depends on experience if and only if experience can override $S$ 's belief that $p .{ }^{21} \mathrm{~A}$ belief is justified a priori if and only if it is not strongly dependent on experience, even if weakly dependent on experience. If this is correct we lose the motivation behind the claim that the a priori is empirically unrevisable for it is grounded on a confusion between strong and weak dependence.

However, we could object that even if we accept this distinction, we could nonetheless claim that weak dependence entails strong dependence in the sense that a belief that is not strongly dependent on experience is also not weakly dependent on experience. If correct, this would mean that a belief that is produced and sustained by a non-experiential process is such that it cannot be experientially rejected. We could then claim that one of the features that distinguish non-experiential from experiential processes of justification is the fact that, contrary to experiential processes, non-experiential processes produce justified belief in all (relevant) counterfactual circumstances. As Kitcher says, "to generate knowledge [or belief] independently of experience, a priori warrants [or processes that confer a priori justification] must produce warranted belief in counterfactual situations where experiences are different" $(1984$, p. 24).

Here is how we could then support such a claim. A priori belief is belief that is justified through a process that is not strongly dependent on the thinker's experience. Processes that justify belief in a way that is not strongly dependent on the thinker's experience are non-experiential. Non-experiential processes have the property of conferring justification upon a belief without relating the thinker to any particular feature of the world - or to use a familiar metaphor, non-experiential processes provide justification without the thinker having to look at the world. It thus seem that provided the experiences necessary for the acquisition of the requisite concepts are in place, plus those that enable the thinker to consider a certain thought, ${ }^{22}$ if a thinker came to believe that $p$ through an a priori process, the thinker would still believe that $p$ in all (relevant) counterfactual circumstances. In other words, the thinker would still believe that $p$ no matter how the actual world turns out to be. ${ }^{23}$ If so, it seems that no

21 A similar distinction is used by Summerfield (1991) and Giaquinto (1996).

22 This proviso is to account for the enabling role that experience might have in the acquisition of a priori belief and knowledge. For example, the reading of a book might prompt a thinker to consider a certain proposition, leading her to believe it after carefully reflecting upon its truth. Nevertheless, such an experience only enables the thinker to consider the thought, and does not play any justificatory role. Experience might thus be necessary for the activation of one's non-experiential processes without playing any justificatory role.

23 This does not entail that a priori beliefs are necessary, at best it entails that a priori true beliefs are, in the useful terminology of Davies and Humberstone (1980) fixedly actually true - i.e., they are true in the actual 
experience a thinker might undergo could override a belief that was produced and justified by a non-experiential process.

Though seemingly compelling, this argument is flawed. From the fact that non-experiential processes are available to justify belief at all (relevant) counterfactual circumstances it does not follow that beliefs produced by such processes are impervious to empirical refutation. For example, imagine that Mary comes to justifiably believe in an axiom after reflecting upon its truth (a purportedly non-experiential process). The process of coming to believe that $p$ through reflection is still available to justify belief regardless of how the actual world turns out to be (provide that the enabling experiences are in place). Now contrast this with a case in which Mary comes to believe that snow is white after seeing white snow (a purported experiential process of justification). In this case, the process of coming to believe in the whiteness of the snow through a visual contact with snow is not available to justify belief regardless of how the actual world turns out to be - other things equal, the process is not available to justify belief at worlds in which snow is not white.

However, even if we accept that a priori processes are available to warrant or justify belief at every (relevant) counterfactual circumstance it does not follow that the beliefs they produce and sustain cannot be empirically overridden. ${ }^{24}$ For example, imagine that I came to believe in the mathematical theorem $T$ after proving it. The process by which I came to believe in $T$ might be available to justify belief at every (relevant) counterfactual situation, and if exercised it would justify my belief that $T$. However, this fact in no way precludes situations in which, say, I meet a leading mathematician who claims that $T$ is false, and whose authority I accept, thus empirically overriding my belief that $T$.

A priori processes might be available to justify belief at every (relevant) counterfactual circumstance, and if activated they would confer justification upon a belief. However, whether or not beliefs so justified are immune to empirical refutation is orthogonal to the notion of a priori justification.

But what to say of those cases in which a thinker is rationally barred from forming an a priori belief due to empirical countervailing evidence? First, it is important to note that such cases do not support the empirical unrevisability of the a priori, for such are not cases in which the thinker revises an a priori belief. Nonetheless, they might be taken to undermine the characterization above

world no matter which world is designated as actual. For more on the relation between the a priori and the fixedly actually true, see my Teixeira (2012). Note, however, that we have no compelling reason to think that a priori false beliefs are not possible.

24 See Casullo (1998) and Summerfield (1991) for a similar claim. 
of an a priori process as a process that is available to justify belief at every (relevant) counterfactual circumstance. But this is not so. Even if the thinker were in possession of subversive evidence, the process would still be available to justify belief, and if activated it would provide the same degree of justification. However, the belief thus produced and justified would be overridden by the subversive evidence, hence precluding the thinker from rationally holding it.

Let me conclude by offering the following characterization of the a priori: ${ }^{25}$ $S$ 's belief that $p$ is justified a priori if, and only if, the belief that $p$ is produced and sustained by a non-experiential process that confers justification upon it. A process is non-experiential if, and only if, it is available to produce and justify belief at every (relevant) counterfactual circumstance (provided the enabling experiences are in place). If this is correct, we have no reason to accept the claim that the a priori is unrevisable - that is, (UT). If so, even if (RT) is true it is perfectly consistent with the existence of a priori knowledge. ${ }^{26}$

\section{Concluding Remarks}

Despite the central role (RT) has played in the debate about the a priori ever since Quine's (1951) influential work, we still lack a strong positive argument in support of (RT). We might be compelled to accept (RT) by those historical examples that lead us to reject claims which were once considered unrevisable. This can indeed be taken to suggest that we can be wrong even about some of our most central beliefs. However, one thing is to be wrong about some of our most central beliefs, another thing is the possibility of being wrong about all of them (though, of course, not all at once). Claims such that at least one belief is revisable does seem to enjoy a special unassailable epistemic status. After all, whatever reason we have to revise it is a reason to endorse it. In any case, the connection between (RT) and the a priori depends on an understanding of the a priori that entails an unrevisability condition, a condition we have no good reason to accept. This suggests that it would be more fruitful if we broke up with tradition and run the debate about the possibility of the a priori independently of (RT). An understanding of the a priori in the way articulated above allows us to do just that.

25 The account being suggested here is similar, in certain respects, to that of Casullo (1998) and Summerfield (1991).

26 Cf. Casullo (1998) and Summerfield (1991). 


\section{References}

BEALER, G. "The incoherence of empiricism". The Aristotelian Society. Supplementary Volume, Nr. 66, pp. 99-138, 1992.

BOGHOSSIAN, P. “Analyticity”. (pp. 331-368). In: B Hale and C. Wright (eds.). Companion to the Philosophy of Language. Oxford: Blackwell, 1997.

BONJOUR, L. "In Defense of Pure reason". Cambridge, UK: Cambridge University Press, 1998.

CASULLO, A. "Revisability, reliabilism, and a priori knowledge". Philosophical and Phenomenological Research, Vol. 49, pp. 187-213, 1998.

. "A Priori Justification”. New York: Oxford University Press, 2003.

CHALMERS, D. "Revisability and conceptual change in 'Two Dogmas of Empiricism"”. Journal of Philosophy, Vol. 108, pp. 387-415, 2011.

DAVIES, M., HUMBERSTONE, L. "Two notions of necessity". Philosophical Studies, Vol. 38, pp. 1-30, 1980.

DEVITT, M. "There is no a priori”. (pp. 105-115). In: E. Sosa, M. Steup (eds.). Contemporary Debates in Philosophy. Oxford: Blackwell Publishers, 2005.

DUMMETT, M. “Is logic empirical?” In: Truth and other Enigmas. Cambridge, Mass: Harvard University Press, 1976.

GIAQUINTO, M. "Non-analytic conceptual knowledge". Mind, Vol. 105, pp. 249268, 1996.

HALE, B. "Abstract Objects". Oxford: Oxford University Press, 1987.

KATZ, J. "Realistic rationality". Cambridge, Mass.: The MIT Press, 1998.

KITCHER, P. "A priori knowledge”. The Philosophical Review, Vol. 89, pp. 3-23, 1980. . "The Nature of Mathematical Knowledge". New York: Oxford University

Press, 1984.

PEACOCKE, C. "The Realm of Reason”. Oxford: Oxford University Press, 2004.

PUTNAM, H. "There is at least one a priori truth". Erkenntnis, Vol. 13, pp. 153-170, 1978. Reprinted in his Realism and reason: philosophical papers, volume 3. Cambridge: Cambridge University Press, 1983. pp. 98-114.

QUINE, W. V. "Philosophy of Logic". Cambridge, Massachusetts: Harvard University Press, 1970.

. "Two dogmas of empiricism". The Philosophical Review, Vol. 60, pp. 20-43, 1951. Reprinted in his From a logical point of view. $2^{\text {nd }}$ ed. Cambridge, MA: Harvard University Press, 1980. pp. 20-46.

. "Carnap and logical truth". Synthese, Vol. 12, pp. 350-374, 1954. Reprinted

in his The Ways of Paradox and Other Essays. Cambridge, Massachusetts: Harvard University Press, 1966. pp. 107-132.

SUMMERFIELD, D. M. "Modest a priori knowledge". Philosophy and Phenomenological Research, Vol. 51, pp. 39-66, 1991.

TEIXEIRA, C. "Metaphysical analyticity". Disputatio - International Journal of Philosophy, Vol. 4, pp. 869-888, 2012. 
TEIXEIRA, C. "Understanding the Revisability Thesis". Grazer Philosophische Studien, Vol. 95, pp. 180-195, 2018.

WILLIAMSON, T. "The Philosophy of Philosophy”. Oxford: Blackwell Publishing, 2007. 